\title{
DIOS SEGÚN HOBBES. INCONSISTENCIAS CON SU FILOSOFÍA MATERIALISTA, MECANICISTA Y NOMINALISTA
}

\author{
God according to Hobbes. \\ Inconsistencies with his materialistic, mechanistic and nominal philosophy
}

Andrés Solano-Fallas ${ }^{1}$

\begin{abstract}
RESUMEN
Este artículo expone analíticamente las inconsistencias que surgen en la filosofía de Thomas Hobbes, en relación con el concepto de Dios, dado que el filósofo inglés lo concibe dentro de su planteamiento materialista-mecanicista. Estas inconsistencias se agrupan en tres puntos concretos de su filosofía: el aspecto propiamente materialista, el mecanicista y el nominalismo. En cada punto, se explica en qué manera el concepto de Dios implica o genera una inconsistencia. Antes de realizar lo anterior, se explica qué es lo que Hobbes concibe como "Dios", como también, la argumentación para indicar su existencia.
\end{abstract}

Palabras clave: Dios, Hobbes, materialismo, mecanicismo, nominalismo, inconsistencias.

\begin{abstract}
This paper analytically exposes the inconsistencies that arise in Thomas Hobbes' philosophy, in relation to the concept of God, since the English philosopher conceives it within his materialistic-mechanistic statements. These inconsistencies are grouped into three specific points of his philosophy: the properly materialistic aspect, the mechanistic, finally, nominalism. At each point, it is explained in what way the concept of God implies or generates an inconsistency. Before doing the above, it is explained what Hobbes conceives as "God", as well as the argument to indicate its existence.
\end{abstract}

Key Words: God, Hobbes, materialism, mechanicism, nominalism, inconsistencies.

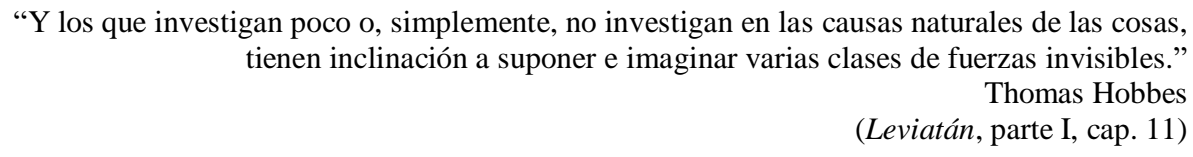

\section{Introducción}

El presente artículo expone cómo Thomas Hobbes incurre en una serie de inconsistencias, que, en algunos puntos, resultan severas para su propia filosofía, al no solo afirmar la existencia de Dios, sino, también, al describirlo. Para ello, se presenta la concepción hobbesiana sobre qué es Dios,

\footnotetext{
${ }^{1}$ Universidad Estatal a Distancia. Docente-tutor de la Escuela de Ciencias de la Educación. Costa Rica.

Correo electrónico: sadsunsea@gmail.com

Recepción: 08-11-2017. Aceptación: 23-11-2017.
} 
para dar cabida a la explicación que el Malmesburiense formula respecto de cómo se afirma la existencia de Dios. Una vez que se realice esto, se inicia con la exposición de las inconsistencias filosóficas, que abarcan desde el plano material y mecanicista, hasta aquello, que si bien no es material, tiene su referente en ello, a saber, el plano nominal.

Lo primero por tratar son las inconsistencias materialistas que se generan a partir de los atributos que Hobbes le confiere a Dios, los cuales no pueden sostenerse sin evitar caer en contradicciones. En segundo lugar, se procede a explicar las inconsistencias mecanicistas, demostrando cómo Dios no compagina con lo que el Malmesburiense establece acerca del movimiento. Por último, se abordan las inconsistencias nominales que surgen al tratar de hacer patente la existencia del vocablo -"nombre", en terminología hobbesiana- "Dios".

\section{Dios}

Este apartado consiste en dos puntos, formulados bajos dos preguntas concretas y concisas. Primeramente, se expone lo que el Malmesburiense cree que se sabe de Dios, o bien, lo que debería saberse. Posterior a esto, se explica cómo Hobbes afirma la existencia del ente divino. Es relevante entender qué es Dios, por cuanto su definición, así como su concepción, es el objeto de trabajo, a partir del cual se exponen las inconsistencias.

\section{1. ¿Qué es lo que Hobbes supone que se sabe de Dios?}

Hobbes presenta a Dios como el Rey de todo el universo, porque gobierna con sus preceptos y amenazas a los hombres, así como con leyes físicas a las demás cosas terrestres. A pesar de que los ateos nieguen la existencia de Dios y otros, si bien admiten su existencia, rechazan su poder para regir las cosas, Dios, ciertamente, existe, como también su providencia. De este modo, su existencia trasciende todo ámbito de aceptación individual, por lo que Dios existe objetivamente:

[L]o quiera o no los hombres, Dios es rey de todo el universo. Aunque haya quienes niegan su existencia o su providencia, no está por eso expulsado de su trono. (...) Solo pertenecen al reino de Dios los que reconocen que Dios es el rector de todas las cosas, que ha dado sus preceptos a los hombres y establece castigos contra los trasgresores (De Cive, cap. 15, art. 2). ${ }^{1}$

Asimismo, posee voluntad, pero en modo alguno como la voluntad humana, a la cual se le llama "deseo racional", debido que atribuirle deseo -como se verá más adelante- implica carencia; y Dios no es carente. Hobbes, llanamente, comenta que por voluntad de Dios "[d]ebemos suponer algo análogo, pero no lo podemos concebir" (De Cive, cap. 15, art. 14 [p. 307]). A pesar de lo laxo de la definición, considera que Dios la manifiesta de tres maneras: 
a) Por los dictámenes tácitos de la razón, que "por ser la naturaleza racional común a todos, se extiende universalmente sobre todos los que reconocen la potencia divina" (De Cive, cap. 15, art. 4).

b) Por la revelación inmediata, la cual "se supone producida por una voz sobrenatural, o por una visión, o por un sueño o por una inspiración o soplo divino" (De Cive, cap. 15, art. 3).

c) Por medio de un profeta, "cuya voz utiliza Dios para significar a los otros su voluntad" (De Cive, cap. 15, art. 3).

Estas tres maneras pueden recibir dos clases de nombres. Por un lado, palabra racional, palabra sensible y palabra profética, respectivamente, si se considera que lo expresado es palabra de Dios. Por otra parte, escucha de la recta razón, escucha de los sentidos y escucha de la fe, respectivamente, si se considera desde el punto de vista que la persona escucha la palabra de Dios.

Con estas maneras, Hobbes evita caer en la afirmación de que todos los hombres aceptan las leyes divinas, independientemente de que acepten o no a Dios y su providencia. En el caso de la primera manera, las leyes solo serán racionales para aquellos que reconozcan la potencia divina. La segunda manera, por su parte, tiene claro que es una palabra que "fue oída por muy pocos hombres" (De Cive, cap. 15, art. 3); y la tercera "es peculiar, porque Dios solo ha dado leyes positivas a su pueblo peculiar y a ciertos hombres por Él escogidos" (De Cive, cap. 15, art. 4). De este modo, con estas especies de "aclaraciones", Hobbes no se ve envuelto en explicar cómo es posible que haya ateos, así como creyentes de Dios, que niegan su providencia, aún cuando Dios expresa su voluntad: no todos los hombres siguen los dictámenes tácitos de razón, no todos reciben una revelación inmediata, y los profetas -al parecer- no tiene alcance práctico universal en la promulgación de leyes. Además, señala que el ateísmo es "una opinión temeraria de la razón" (De Cive, cap. 16, art. 1). Dado que Hobbes engloba grupalmente a los ateos junto a esta clase de creyentes, cabría extenderles esta consideración. Así, estos creyentes niegan la providencia por la misma causa que los ateos niegan la existencia de Dios: por temeridad de su razón.

Lamentablemente, para los ateos, como también para esta clase de creyentes, Dios tiene derecho natural de reinar sobre ellos y castigarlos, ya que su poder es "irresistible" y "la naturaleza no lo suprime" (De Cive, cap. 15, art. 5). ${ }^{2}$ Dios tiene el derecho natural de gobernar, pues la misma naturaleza reconoce el derecho del más fuerte. Además, el más fuerte no está obligado a entregar su poder. De ahí que, al ser Dios Todopoderoso, "su derecho de dominar deriva de su mismo poder" (De Cive, cap. 15, art. 5), por lo que a todos los hombres, sean o no ateos, sean o no de esta clase de creyentes, no les queda más que obedecer, debido a su debilidad (De Cive, cap. 15, art. 7).

De lo anterior, se tiene que Dios es un ser todopoderoso, cuyo derecho a gobernar el universo no deriva de que su poder sea sobrenatural; por el contrario, es naturalmente superior, por dos razones. La primera razón consiste en que ninguna criatura puede igualar al poder de Dios; la segunda razón, en que "el cielo la tierra y todas la criaturas obedecen a las leyes comunes de su creación" (De Cive, cap. 15, art. 7). Esto último permite afirmar que Dios también es causa del mundo, de lo contrario, se 
negaría que Dios exista: si Dios no es causa del mundo, Dios no existe (De Cive, cap. 15, art. 14 [p. 306]). Bajo este entendido de que Dios es la causa del mundo, Hobbes impugna a aquella clase de creyentes que niegan la providencia, en tanto postula que Dios no es indiferente a la dirección del mundo y del género humano (cf. De Cive, cap. 15, art. 14 [p. 307]).

Luego, señala que Dios es infinito (De Cive, cap. 15, art. 14 [p. 307]; también en Leviatán, parte I, cap. 12). Pero esta afirmación no significa que el entendimiento humano ${ }^{3}$ tenga una idea de tal voz, sino que muestra su impotencia, ya que el entendimiento humano puede concebir únicamente lo finito. Nótese que en De Cive, Hobbes se refiere a este atributo como 'voz', en lugar de 'concepto'. Solo es posible derivar el concepto de la experiencia sensible, es decir, de cosas finitas. De ahí que 'infinitud' no exprese un concepto sino, antes bien, un término: algo que se dice respecto de Dios, pero sin implicar su conceptualización.

En este sentido, apunta que Dios no tiene partes, porque cualquier cosa que tenga partes denota finitud. Por la misma razón, no puede decirse que Dios sea un todo, porque el todo implica la finitud. Tampoco puede aseverarse que se encuentra en un lugar, porque "cualquier cosa que se halla en un lugar es limitada y finita en su grandeza" (De Cive, cap. 15, art. 14 [p. 307]). Ni mucho menos enunciar que Dios se mueve o reposa, porque el movimiento o el reposo suponen la ubicación de aquello que se mueve o de aquello que reposa en un lugar. Contra cualquier politeísmo, rechaza que puedan existir varios dioses, debido a que es imposible la existencia de varias "cosas" infinitas (De Cive, cap. 15, art. 14 [p. 307]). Si existiesen, no serían infinitos, porque en algún punto se limitarían.

En cuanto a las emociones, solo puede afirmarse que posee felicidad, pero sin saber en qué consiste, ya que, acto seguido, pasa a enumerar qué es indigno atribuirle a Dios. En primer lugar, no puede asignársele dolor como arrepentimiento, ira y compasión, sino solamente "por metonimia, como el efecto" (De Cive, cap. 15, art. 14 [p. 307]). En segundo lugar, no puede atribuírsele "la necesidad", tales como el apetito, la esperanza, la concupiscencia y el deseo, "porque indican carencia y es imposible concebir que alguien desee, espere o ambicione algo que no necesita ni le hace falta" (De Cive, cap. 15, art. 14 [p. 307]). En tercer lugar, tampoco puede otorgársele una facultad pasiva, "porque sufrir es propio de una potencia limitada y dependiente de otra" (De Cive, cap. 15, art. 14 [p. 307]).

Respecto de los antropomorfismos bíblicos, como los actos de los cinco sentidos, el conocimiento y el entendimiento, no puede atribuírsele de la misma manera, ya que en los hombres son "una turbación de la mente suscitada por las cosas externas que ejercen su presión sobre los órganos" (De Cive, cap. 15, art. 14 [p. 307]). Si se le atribuyesen a Dios tal cual, serían un signo de dependencia a otra potencia, a saber, las cosas externas.

Debido a lo anterior, considera que quien desee darle atributos a Dios, debe utilizar las siguientes tres clases de atributos que la razón manda: a) atributos negativos, tales como: infinito, eterno, incomprensible; b) atributos superlativos, tales como: óptimo, máximo, altísimo, fortísimo; y c) atributos indefinidos, tales como: bueno, justo, fuerte, creador, rey y semejantes (De Cive, cap. 15, 
art. 14 [p. 307-308]; también en Leviatán, parte II, cap. 31). No obstante, aclara que estos atributos no pretenden enunciar lo que Dios realmente es, sino declarar admiración y obediencia, puesto que para Hobbes "[t]ampoco se debe disputar acerca de la naturaleza de Dios", porque la razón "se halla tan lejos de enseñarnos algo de la naturaleza de Dios que ni siquiera nos enseña suficientes cosas de las propiedades de nuestro cuerpo o de cualquier otra criatura" (De Cive, cap. 15, art. 15). ${ }^{4}$ Lo único que puede saberse de su naturaleza es "que es", de ahí que la razón dicte un solo nombre para significarlo, a saber, "existente" (De Cive, cap. 15, art. 14 [p. 308]).

Empero, ¿qué clase de "existente” es?, ¿será inmaterial? Para el Malmesburiense, Dios es una substancia, siendo esto lo más importante por tener en cuenta, para mostrar las inconsistencias en su filosofía materialista-mecanicista. A diferencia de teólogos medievales y de sus contemporáneos que insistían en que Dios carece de materialidad (cf. Alonso, 2011; Glover en Brown, 1965; Solano-Fallas, 2015), Hobbes afirma lo contrario, en orden a incluirlo en su materialismo, para no ser inconsistente consigo mismo. ${ }^{5}$ A modo de ejemplo, en las objeciones que sostuvo contra las Meditaciones de Prima Philosophia (1641), de René Descartes, se tiene que el filósofo francés le replicó -a la Objeción II que Hobbes le planteó- lo siguiente: "todos los lógicos, y con ellos casi todo el mundo, suelen decir que unas substancias son espirituales y otras corpóreas" (Descartes, citado en Descartes, 1977, p.142). Hobbes le recrimina, en la Objeción XIV, el uso que ha hecho de la palabra 'substancia', respondiéndole que "la esencia sin existencia es una ficción de nuestro espíritu" (Hobbes, citado en Descartes, 1977, p.157). Es decir, a diferencia de Descartes, quien plantea dos tipos de substancias, entendiendo por este concepto dos clases ónticamente distintas una de la otra, el Malmesburiense afirma que solo existe un tipo, por razón de lo cual todo lo noético es corpóreo.

En otras palabras, lo anterior conduce a postular que lo único que existe es aquello que posee materialidad. Por ello, el nombre que le otorga a Dios es 'existente', para significar su naturaleza: "algo" material que existe, que es. En la réplica que realiza Hobbes al exobispo de Derry, Dr. Bramhall, ${ }^{6}$ el Malmesburiense remarca que Dios es "an infinitely fine Spirit" (Hobbes, 1741, vol. IV, p. 310). En una primera vista, parecería que Hobbes estaría cayendo en la argumentación cartesiana de separar cuerpo (materia) y espíritu, al plantear que Dios es espíritu, sin afirmar expresamente que es material. No obstante, en dicha réplica, momentos antes, ha definido que el "Spirit is thin, fluid, transparent, invisible body" (Hobbes, 1741, vol. IV, p. 309), por lo que Dios es material, con la particularidad que es mucho más sutil y fluido que los demás cuerpos; razón por la cual, ninguno de los sentidos corporales puede percibirlo, a pesar de haya dicho que una de sus maneras para expresar su voluntad es la palabra sensible o la escucha de los sentidos. 


\title{
2.2. ¿Cómo llega a afirmar la existencia de Dios?
}

Según el Malmesburiense, Dios supera al ser humano y le es completamente independiente, lo cual conduce a la conclusión de que también lo divino es el creador, tanto del ser humano, como del mundo. Hobbes afirma lo anterior basándose en la cadena de causas y efectos, las cuales jamás pueden proseguir al infinito. La razón que ofrece es simple:

\begin{abstract}
La curiosidad, o amor al conocimiento de las causas, lleva a un hombre a buscar una causa partiendo de la consideración de un efecto; y una vez encontrada esa causa, a buscar la causa de ésta. Y así, hasta llegar al pensamiento de que debe haber necesariamente alguna causa primera, incausada y eterna. A esto es a lo que los hombres llaman dios. Por consiguiente, es imposible que hagamos una investigación profunda de las causas naturales, sin ser llevados a creer que hay un Dios eterno (Leviatán, parte I, cap. 11).
\end{abstract}

Como puede apreciarse en el texto, Hobbes recurre al argumento cosmológico, concretamente a la especie de argumento de las causas eficientes, dado que no solo supone la existencia de Dios a partir del análisis que opera sobre el mundo, sino que hace que ese Dios le confiera orden. Cabe añadir que en el citado capítulo 11 del Leviatán se hace manifiesta la misma incomodidad que imperaba en Francisco Suárez: argumentum ad absurdum. ${ }^{7}$ Posiblemente, se deba a que resultaría imposible para Hobbes que el ser humano conociese ${ }^{8}$ ya que al ser su conocimiento finito, no se sabría cuál sería la causa del último efecto conocido. Al no conocerse esta causa, no se podría saber el efecto; y al no saberse ese efecto, no se le podría considerar causa del efecto siguiente; así continuamente. De ahí que sea necesario tomar a Dios como causa primera, para garantizar la cadena causal del conocimiento. Tal vez, por esta razón, afirma que el ser humano se siente inclinado a creer en que hay un Dios, en orden a conocer con profundidad las causas naturales.

\section{Inconsistencias materialistas}

Para el Malmesburiense un cuerpo es "todo lo que independientemente de nuestro pensamiento coincide con alguna parte del espacio o se coextiende con ella (sic)" (De Corpore, cap. 8, art. 1), puesto que ocupa un espacio, posee extensión finita, el cual es conocido por su cantidad. Hobbes define esta última como "una dimensión determinada, o una dimensión cuyos límites son conocidos por el lugar o por alguna comparación" (De Corpore, cap. 12, art. 1). Pero ¿cómo es determinada? Dice que lo es por dos maneras: la primera es por los sentidos; la segunda es por la memoria, la cual supone que realiza una comparación con una experiencia pasada.

¿Puede lo anterior ser compatible con lo que propone de Dios, a saber, que es un cuerpo? Claramente, no. La razón se debe a lo que él mismo ha dicho sobre lo que determina la cantidad de un cuerpo. De acuerdo con la primera manera, resulta imposible poder determinar la cantidad de su 
supuesto cuerpo a través de los sentidos, por lo cual no es cuestión de que trascienda la experiencia sensible, sino que simplemente no se da. A pesar de su propia proposición, Hobbes trató de hacer caso omiso de ella. Lo mismo sucede con la segunda manera. Dado que la memoria proviene de los sentidos, ${ }^{9}$ es igualmente imposible recordar el cuerpo divino si nunca se ha tenido experiencia de él.

El punto anterior no es el único que muestra cómo pretendió forzar su filosofía. También lo hace en lo que respecta al tema de la causa. En el artículo 14 del capítulo 15 de De Cive, según se mencionó, Hobbes afirma que Dios es la causa del mundo. Empero, no explicó qué ha de entenderse por causa. Comencemos por lo que entendió en De Corpore. Indica que un efecto no se produce porque un cuerpo sea cuerpo, sino por los accidentes. ${ }^{10}$ Entonces, para que se dé un efecto, son indispensables tanto los accidentes del cuerpo agente como los del paciente. Para ser más específico en esta cuestión, expresa:

$\mathrm{Al}$ conjunto de accidentes, tanto del agente o de los agentes como del paciente, requeridos para que se produzca el efecto, se llama, una vez producido, causa eficiente. Y al conjunto de los que se encuentran en el paciente se llama, una vez producido el efecto, causa material (De Corpore, cap. 9, art. 4).

Tanto la causa material como la causa eficiente conforman la causa íntegra, la cual es el agregado de todos los accidentes. Establecido esto, se aborda la inconsistencia. En el capítulo 12 del Leviatán, Hobbes expresa que Dios es la causa primera de todas las cosas; ¿inconsistente?, sin duda alguna, ya que no es posible establecer una causa primera de la cual todo lo demás descienda, sea directa o indirectamente, debido a la misma definición que ha dado de causa eficiente: conjunto de accidentes de ambos cuerpos; por lo cual ninguno (cuerpo o un accidente de entre varios de un cuerpo) tiene primacía. Dios no puede ser la causa íntegra, debido a que su conformación depende de los accidentes del agente como del paciente, sin que exista una jerarquización óntica. Es decir, Hobbes no otorga algún status óntico de superioridad a algunos cuerpos, por ende, a sus respectivos accidentes. El ordenamiento causal depende de la manera en que se produzca cada efecto. Aun concediendo el hecho de que se considere a Dios como causa eficiente, no tendría primacía sobre todas las cosas, debido a que la causa eficiente requiere del conjunto de accidentes del paciente, es decir, de la causa material; por lo que estaría en codependencia no jerárquica de otras causas.

Pasemos a otro asunto, que claramente evidencia otra inconsistencia. Hobbes afirma tanto en el artículo 14, del capítulo 15 de De Cive -como también en el mismo capítulo 12 del Leviatán-que Dios es infinito. Para que tal proposición se dé en la realidad, requeriría que nada existiese, ya que cualquier cuerpo constituye un límite a esa supuesta infinitud. De esta manera, la misma definición de cuerpo del Malmesburiense viene a mostrar su fallido intento.

Continuando con la exposición de la inconsistencia en torno de la infinitud, indica en el artículo 7, del capítulo 9 de De Corpore, lo siguiente: "No puede hallarse causa alguna del movimiento más que en un cuerpo contiguo y en movimiento". De lo que interesa por el momento - 
este artículo será también tratado en la parte del mecanicismo-, es lo dicho respecto del cuerpo, a saber, que un cuerpo contiguo supone la existencia de otro. Por más simple que lo anterior parezca -y tal vez redundante- en dicho artículo, Hobbes está apuntando a que los cuerpos han de ser finitos. Por tanto, no solo su concepción de Dios infinito nuevamente se desquebraja, sino que no puede considerarse que sea un cuerpo, debido que al no ser un cuerpo, no es nada.

Por último, su aseveración de que Dios es el creador del mundo conduce a la afirmación de que la materia tuvo un comienzo. No obstante, Hobbes considera que los cuerpos son ingenerables, debido a que lo que se genera y se corrompe son los accidentes:

[E]s claro que todos los demás accidentes, excepto la magnitud o la extensión, se pueden generar y perecer. (...) Por eso los cuerpos y los accidentes bajo los que aparecen de diversas formas difieren de tal manera que los cuerpos sean cosas no engendradas y los accidentes engendrados pero no cosas (De Corpore, cap. 8, art. 20).

Además, si la materia no es engendrada, ¿qué necesidad hay de incluir un Dios? No es posible concebir que un $\mathrm{X}$ que sea ingénito, debiendo su existencia a sí mismo, a su vez no sea un ser necesario por sí, ya que su existencia dependería, en última instancia, de otro ser, sea de manera directa o indirecta. Empero, el asunto continúa, ya que expresa que no puede "alabar a los que se jactan de haber demostrado con sus razones tomadas de las cosas naturales que el mundo ha tenido un comienzo" (De Corpore, cap. 26, art. 1). En otras palabras, estamos ante el mismo absurdo que Tomás de Aquino planteó en su De aeternitate mundi contra murmurantes: el mundo es eterno, pero fue creado. ${ }^{11}$ Mientras postula que Dios es el creador del mundo, indica que los cuerpos no son engendrados. Cabe presuponer válidamente que esta afirmación la realiza analizando los cuerpos que la propia naturaleza le presenta, por lo que, de algún modo, él mismo estaría jactándose de demostrar que Dios es causa a partir de razones tomadas de las cosas naturales. A diferencia del Aquinatense, Hobbes omite ofrecer mayores disparates como explicación -evitando debilitar aún más su filosofía-, al enunciar lo siguiente:

$[\mathrm{P}]$ aso por alto conscientemente las cuestiones acerca de lo infinito y lo eterno, contento con la doctrina sobre la magnitud y el origen del mundo de la que me han persuadido las Sagradas Escrituras y la fama de los milagros que las confirman, así como las costumbres de mi patria y la reverencia debida a la leyes; y paso a otras cosas que no es ilícito discutir (De Corpore, cap. 26, art. 1).

No obstante, lo anterior no lo exonera de uno de los vicios en los que se incurre de acuerdo con el artículo 18, del capítulo 6 de De Corpore: Petición de principio. Aunque no manifiesta expresamente que sus lectores también han de creer lo mismo que él, supone que tal tema es ilícito. Por otra parte, puede decirse que su intento de considerar a Dios como un "algo material" resultó infructuoso. Por su afán de realizar dicha inclusión, le acarreó como consecuencia un serio tambaleo a su materialismo, ya que hizo caso omiso de principios fundamentales de la materia, expuestos por él mismo. 


\section{Inconsistencias mecanicistas}

Antes de evidenciar las inconsistencias sobre Dios, desde su concepción mecanicista, debe aclararse que Hobbes no explicita el vínculo entre Dios y el movimiento. Como afirma Moya-Bedoya (2012), no puede afirmarse que Hobbes haya dicho que Dios sea el primer motor, debido a que es un punto al cual no se refiere. Sin embargo, cabe inferir, a partir del apartado anterior, que Hobbes concebía a Dios como la causa última del movimiento, a pesar de su silencio en este tópico.

\subsection{Inferencia sobre Dios como causa última del movimiento}

En primer lugar, si se toma en conjunto lo expresado en el artículo 14, del capítulo 15 de De Cive, y el capítulo 12 del Leviatán, a primera vista, se obtiene que Dios es la causa del mundo, así como la causa primera de todas las cosas. Según esto, todo, en última instancia, tiene su razón de ser por Dios, por lo cual se infiere que también es la causa originaria del movimiento. A pesar de que en el artículo 7, del capítulo 9 de De Corpore, haya establecido que "[n]o puede hallarse causa alguna del movimiento más que en un cuerpo contiguo y en movimiento", cabe preguntarse qué fue lo que originó ese movimiento. Este artículo de De Corpore lo que expresa es dónde se halla el movimiento, según causas asequibles a la experiencia, pero no se refiere a que la causa última del movimiento se reduzca a la contigüidad de los cuerpos movientes. Leyendo este artículo de De Corpore, a la luz de De Cive y del Leviatán, el movimiento no puede tener su causa última en la contigüidad de los cuerpos movientes, sino en Dios.

En segundo lugar, y reforzando lo anterior, de acuerdo al capítulo 11 del Leviatán, para el Malmesburiense, cuando se obtiene la conclusión de la existencia de Dios, se debió a la imposibilidad de proseguir al infinito, en razón del "amor al conocimiento de las causas", por lo que irremediablemente se llega "al pensamiento de que debe haber necesariamente alguna causa incausada y eterna", a lo cual "los hombres llaman dios". Siguiendo esta línea argumentativa, cuando se pregunta por el origen del movimiento -no dónde se halla para la experiencia directa-, parece plausible suponer que Dios es su causa, ya que Él es lo último a lo cual nada más se pueda remitir.

De este modo, cabe inferir que Hobbes considera a Dios como la causa última del movimiento: aquello que explicaría el origen del movimiento, ya que Él es la causa incausada y eterna, la causa del mundo, así como la causa primera de todas las cosas. Es decir, por lo expuesto, Dios no podría no ser el titular de la causalidad del movimiento, a pesar de que el Malmesburiense no lo explicitase. 


\subsection{Inconsistencias generadas en su filosofía}

Explicada la inferencia de que Dios es la causa última del movimiento, puede darse paso a exponer las inconsistencias que esto implica para su filosofía. Como primer punto, se tiene que el Malmesburiense trata de eximir a Dios de movimiento y reposo (De Cive, cap. 15, art. 14 [p. 307]), porque desde su concepción, el movimiento y el reposo solo se dicen de cosas finitas. Empero, resulta conflictivo hacer esta exención de movimiento a Dios, cuando se ha inferido de lo anterior que Dios es la causa del movimiento. En otras palabras, ¿cómo un ser que es la causa última del movimiento no tiene relación alguna con el movimiento? Es decir, si el movimiento no puede remitirse a Dios, ¿entonces cuál sería la causa última del movimiento? Recuérdese que, en Hobbes, no puede realizarse ninguna atribución que esté fuera de las cadenas de causa y efecto. De esta manera, el filósofo no logra compaginar que su Dios sea causa de movimiento, pero, a la vez, esté eximido del movimiento. Esto presenta un quiebre en la cadena, porque para Hobbes ser exento de movimiento implica no tener ninguna relación con el movimiento, ya que conduciría a preguntarse cómo algo es causa, por ende, tiene efecto en los demás cuerpos, cuando ha sido desligado de esa cadena causal, al no ser partícipe de movimiento.

Como segundo punto, se tiene que cuando consideró a Dios como substancia -se sobreentiende que material-, dicha pretensión de eximirlo de movimiento y reposo entra en contradicción con el citado artículo 7, del capítulo 9 de De Corpore, a partir del cual se infiere que toda substancia está sujeta a las leyes mecánicas, como cualquier otro cuerpo. De acuerdo con este artículo, Dios no podría ser la causa última de movimiento, porque el movimiento propiamente se halla en los cuerpos contiguos y en movimiento. Esto supondría que el movimiento es connatural a los cuerpos en su contigüidad, por lo cual no habría necesidad de escalar más allá de la cadena causal, que se le presenta a la experiencia inmediata y mediata. Consiguientemente, no tendría sentido que Hobbes haya supuesto a Dios como causa primera de todas las cosas. Desde el propio Malmesburiense, el movimiento puede explicarse desde la contigüidad de los cuerpos, por lo tanto, él mismo incurre en una contradicción, al forzar que se deba llegar al pensamiento de que debe haber necesariamente alguna causa llamada "dios".

Al ser Dios una substancia, sería una causa o efecto de movimiento, como cualquier otra sustancia, ya que un cuerpo se mueve por el contacto con otro, en razón de lo siguiente:

[L]o que está en reposo permanecerá siempre en reposo a menos que exista algo fuera de ello, por cuya causa no pueda permanecer más en reposo; y lo que se mueve se moverá siempre, a menos que exista algo fuera de ello, que impida su movimiento" (De Corpore, cap. 15, art. 1). 
El problema reside en que ningún cuerpo puede moverse a sí mismo, ${ }^{12}$ por tanto, tampoco se puede suponer ser la causa última del movimiento de los demás cuerpos. Si Dios es el primer motor, entonces en la medida en que mueve, él se mueve, asumiendo que sea un cuerpo (aunque ya se comentó que no puede darse, debido a que no cumple con lo que el mismo Malmesburiense ha dicho de qué es un cuerpo). Y si tal es el caso, entonces no puede aseverarse que Dios sea inconmutable. Así, pues, si Dios es el primer motor, entonces Dios no es inconmutable; y si Dios es inconmutable, entonces Dios no es el primer motor. Por ello, no puede aseverarse que Dios sea la causa primera del movimiento de los entes y un ente inconmutable.

De este modo, puede notarse cómo habría fracasado en su intento, dadas las inconsistencias que implicarían haber explicitado a Dios como causa última del movimiento. Dios no puede ser dicha causa, sin regirse por las leyes mecánicas, debido a que, supuestamente, es materia; pero tampoco puede ser tal causa, ya que de ser un cuerpo, movería y sería movido como los demás, es decir, dependería de otro cuerpo, estando inmerso en las cadenas de causa y efecto. Especulativamente, puede comentarse que, quizá, en este punto (de Dios y su relación con su planteamiento mecánico), Hobbes, por lo menos, avistó estas inconsistencias; de ahí que decidiera no explicitar su concepción de Dios como tal causa de movimiento.

\section{Inconsistencias nominalistas}

Para este último apartado, se muestra, paulatinamente, la propuesta nominalista de Hobbes para visualizar poco a poco cómo Dios no es nada. Por el momento, lo que puede adelantarse es que el razonamiento no opera sobre los cuerpos mismos, sino sobre los nombres. Esto se debe a que un cuerpo puede ser considerado según diversos nombres. Tal diversidad la reduce a cuatro apartados generales (ver Leviatán, parte I, cap. 4): el primero concierne a cuerpos (en un modo general: la materia); el segundo, a los accidentes de esos cuerpos; el tercero atañe a las propiedades del cuerpo humano, por las cuales realizamos distinciones; y la cuarta no pertenece a los cuerpos, sino a los nombres que se dan a los nombres mismos, como a los lenguajes.

Toda esa variedad agrupada en cuatro apartados generales es reducida aún más, ya que se clasifican en nombres positivos y negativos. Los primeros son los que:

Se imponen por su semejanza, igualdad, o identidad, y negativos los que se imponen por la diversidad, desemejanza o desigualdad de las cosas pensadas. (...) [Además,] los positivos son anteriores a los negativos porque sin aquellos el uso de estos no podría darse (De Corpore, cap. 2, art. 6 y 7, respectivamente).

En otras palabras, el negativo designa, prácticamente, cualquier cosa, ya que es contrario a lo concreto que se designa con el positivo. Debe aclararse que, por concreto, no se refiere que sea necesariamente exclusivo a algo "propio" (en específico), por ejemplo, que el nombre "gato" solo 
pertenezca a un gato llamado Muri, sino que también refiere a un nombre "común" a varios entes, como la misma palabra "gato". En cuanto al nombre negativo, dice que puede ser cualquier cosa, debido a que un solo nombre negativo no puede abarcar todas las desemejanzas que haya, o pueda haber, con uno positivo. Por tanto, un nombre negativo puede ser tanto definido o indefinido.

Siguiendo lo anterior, puede afirmarse que Hobbes no fue consecuente, porque define a Dios como infinito, incomprensible, omnipotente, entre otros. Pero si se presta atención, se observa que no son más que negativos, ya que "sirven para significar que una palabra no es el nombre de la cosa en cuestión" (Leviatán, parte I, cap. 4). Como se ha mostrado, no es posible que algo pueda ser omnipotente, ya que sería excluirlo del mecanicismo que rige en su materialismo. Tampoco que sea infinito, ni que nada infinito exista; a lo cual hay que añadir que en los ejemplos que él cita como nombres negativos se halla 'infinito', cayendo en contradicción por el peso de su propia pluma. A su vez, que algo sea incomprensible conduce a suponer que no se encuentra en la naturaleza, es decir, que no está bajo el mando de los procesos mecánicos ni que es material (o que ni siquiera posee un referente material).

Con todos estos nombres, se aprecia que ninguno corresponde a algo existente, razón por la cual han de considerarse que son negativos, ya que lo material es comprensible y finito, por ende, limitado en su potencia. Dado que nombres negativos no se usan en relación con algo, sea concreto "propio" o concreto "común", se ha de concluir que Dios no existe, lo cual permite visualizar el forzamiento que Hobbes realizó en su nominalismo.

En aras de evidenciar más su inconsistencia, momentáneamente, otorguémosle a Dios su existencia: ¿es acaso demostrable que exista? Téngase en cuenta que de los dos conocimientos, el de hechos y de consecuencias, Hobbes considera que el último es el que se requiere del filósofo. Ello se debe a que el primero es un conocimiento absoluto, es decir, como cuando se ve realizar un hecho o se recuerda que fue; mientras que el segundo permite indagar, debido a que conducen de una afirmación a otra. En otras palabras, el conocimiento de consecuencias conduce al silogismo, dado que el silogismo busca establecer la consecuencia que se sigue de un dicho a otro, a partir de definiciones, las cuales son lo que se conviene como verdadero y falso; parecería que no se podría decir nada en contra de Dios, ya que "la verdad reside en lo dicho, no en la cosa" (De Corpore, cap. 3, art. 7) (asumiendo que Dios sea una cosa). No obstante, la trampa argumentativa se halla en lo que Hobbes entendió por 'definición': "verdades establecidas al arbitrio del que habla y del que oye y, por lo tanto, indemostrables" (De Corpore, cap. 3, art. 9). De esta manera, no cuestionó la definición de "Dios", sino que empezó a formular sus silogismos a partir de Dios. No obstante, su escapatoria tiene una grave consecuencia: todo lo que se diga de Dios o, incluso, el mismo nombre "Dios" no es verdadero, pero tampoco es falso. Simplemente no es nada: los hombres crean la palabra y la dotan de contenido.

Por tanto, Dios no existe. Al no ser nada, no tiene ningún argumento para afirmar que existe, ni mucho menos para aseverar que es eterno, sin ninguna división. Esto lo complementa y respalda su 
propio materialismo, ya que todo conocimiento humano se desarrolla a partir de lo sensible, por lo que tampoco podría mantener los nombres negativos que le ha otorgado a Dios, ni a Dios mismo, "[p]ues no hay ninguna concepción en la mente humana que en un principio no haya sido engendrado en los órganos del sentido, total o parcialmente" (Leviatán, parte I, cap. 1).

Al no ser materialmente nada, ni mucho menos nominalmente, todo lo que señaló de que Dios es el rey de todo el universo, así como que puede castigar a todos los hombres, incluyendo a los ateos y a la clase de creyentes que rechazan "su" providencia, pierde valor. No existe absolutamente ningún ser divino; consiguientemente, Hobbes tendría que retractarse de tales atributos. Irónicamente, indica que uno de los errores que la gente comete es el otorgarle existencia al nombre que utiliza para referirse a algo, ya que puede usarse un nombre tanto para una cosa, como para una imagen o una ficción: ${ }^{13}$

Pero como todo nombre tiene relación con algo nombrado, aunque lo nombrado no siempre sea una cosa que existe en la naturaleza de las cosas, será lícito, en razón del sistema, llamar cosa a lo nombrado como si fueran lo mismo, ya exista tal cosa o sea fingida (De Corpore, cap. 2, art. 6).

Se aprecia, entonces, que Hobbes comete el mismo error. Cabe preguntarse: ¿por qué? La respuesta la ofrece él mismo: "esto solo ocurre entre quienes conversan sobre cuestiones que se refieren a asuntos incomprensibles" (Leviatán, parte I, cap. 8).

\section{Conclusión}

No cabe duda que Hobbes fuerza su filosofía al punto de cometer inconsistencias, afectándola severamente, por ende, poniéndola en detrimento. El Malmesburiense pareció olvidar, o hacer caso omiso, a lo que él mismo expresó acerca de este tema:

Tampoco se debe disputar acerca de la naturaleza de Dios. Se ha supuesto que en el reino natural de Dios todo es examinado por la sola razón, es decir, por los principios de la ciencia natural. Ahora bien, ésta se halla tan lejos de enseñarnos algo de la naturaleza de Dios que ni siquiera nos enseña suficientes cosas de las propiedades de nuestro cuerpo o de cualquier criatura (De Cive, cap. 15, art. 15).

Hobbes trató de ser lo más sistémico y rígido posible en los tratados que se emplearon. En De Cive, así como en De Corpore, se ve que escribe a modo de artículos - no tan disciplinado en comparación con Spinoza-, y que en el Leviatán, si bien, no lo maneja de la misma manera, lo organizó por partes, que se suponen van desde lo más básico (Del hombre) a lo complejo (Del reino de las tinieblas), repitiendo en cada parte la misma graduación de complejidad. Sin embargo, no solo 
prefiere subordinar su filosofía a su creencia, sino que la rebaja a decir que no enseña lo suficiente sobre cualquier cuerpo.

Esta insistencia de abordar, reiteradamente en sus obras, un tema que él mismo recomienda no ahondar, dada la imposibilidad de comprensión por parte del intelecto humano, conduce a la valoración de que "[1]a idea de Thomas Hobbes como un pensador ateo ya no se sostiene" (Alonso, 2011, p. 389). La problemática inclusión de Dios en su filosofía materialista-mecanicista no parece ser un asunto gratuito en el pensamiento del Malmesburiense; mucho menos puede aseverarse que Hobbes "inserta" a Dios en su filosofía solamente para evitar una acusación de ateísmo. ${ }^{14} \mathrm{Si}$ este hubiese sido el caso, considero que a Hobbes le hubiese bastado concordar con la ortodoxia anglicana de su tiempo, ahorrándose, a su vez, las serias inconsistencias que su conceptualización de Dios generó en sus planteamientos.

\section{Notas}

1. Respecto de la citación, este artículo se aparta parcialmente del formato APA, en lo concerniente únicamente a las obras hobbesianas, debido a la particular manera en que están escritas. Dado que Hobbes trató de sistematizar sus obras acorde al modo "geométrico" de su época, se indica el nombre de la obra en cursiva, seguido de la parte o capítulo -dependiendo de cómo esté estructurada la obra en cuestión-, seguido del número del artículo -si la obra en cuestión viene enumerada en artículos-. Solo en determinados casos, cuando el capítulo o artículo sea demasiado largo, se anota el número de página -sin hacer referencia al año de la edición, para lo cual puede consultarse la referencia bibliográfica-. Ejemplos de lo anterior: De Cive, cap. 15, art. 14 [p. 307] o Leviatán, parte I, cap. 12 .

2. Es más, quienes no admitan "en presencia de hombres, por palabras y acciones, que hay un Dios único, óptimo, máximo, beatísimo, rey supremo del mundo entero y de los reyes del mundo, es decir, si no honran a Dios (...) es crimen de lesa majestad (...] pues consiste en negar el poder divino y constituye ateísmo" (De Cive, cap. 15, art. 19). De este modo, no solo los ateos cometen este crimen, sino también aquella clase de creyentes que niegan la providencia (cf. De Cive, cap. 18, art. 11).

3. En el Leviatán utiliza "pensamiento" en vez de "entendimiento".

4. Si bien no puede disputarse acerca de la naturaleza de Dios, "el Estado, esto es, aquellos que detentan el poder en el Estado, juzgará legítimamente qué nombres o apelaciones son o no son honoríficos para Dios, es decir, qué doctrinas deben aceptarse y confesarse públicamente respecto a la naturaleza de Dios y de sus operaciones" (De Cive, cap. 15, art. 16). Hobbes explica esto mediante el pacto: una vez que se ha trasferido a aquel o aquellos que detentan el poder soberano en el Estado tanto derecho de gobernarse, se debe de concluir que también se transfirió el derecho de decidir sobre aquellas cuestiones. Es más, "no va contra la voluntad de Dios, manifestada por la sola razón, tributarle los signos de honor que mande el Estado" (De Cive, cap. 15, art. 17); excepto si el Estado ordena ofender directamente a Dios o no rendirle tributo, no se le ha de obedecer (De Cive, cap. 15, art. 18).

5. A criterio de Glover (en Brown, 1965, p. 144), Hobbes no encuentra inconvenientes serios de incluir a Dios en su planteamiento materialista, dado que su materialismo no es de carácter atomista. De acuerdo con Glover, esto le da ventajas explicativas al Malmesburiense, tales como indicar que Dios es efectivamente corpóreo, pero sutil; como también que al ser corpóreo, puede comprenderse mejor la dinámica de su providencia, en la medida en que siendo cuerpo, puede mover (a su manera) otros cuerpos. A la valoración de Glover, cabe explicitar que un materialismo no-atomista, le evita hacer de Dios una conformación de átomos, por consiguiente, desagregar su ser.

Aunado al asunto de ser consecuente consigo mismo, considero que el Malmesburiense también se vio motivado por su convicción-creencia de que el cosmos solo puede comprenderse en clave matemática, por tanto, que todos los movimientos que acaecen han de explicarse con base en leyes mecánicas (Solano-Fallas, 2015, pp. 102-103). En este sentido, Dios no podía ser dejado de lado, por lo que tenía que hacerlo partícipe del mecanicismo cósmico. Sintomática es la dedicatoria en De Cive, en la que expresa que "lo que diferencia el tiempo presente de la barbaridad antigua, casi todo se lo debemos a la geometría" (Hobbes, citado por Rodríguez-Feo, en Hobbes, 2000, p. 17). 
6. Esta réplica se debe a que el Dr. Bramhall escribió un libro, The Catching of the Leviathan, en el que, a criterio de Hobbes, lo acusa de ateísmo e impiedad, tergiversando citas tomadas de su Leviatán.

7. Este argumento es expuesto por Suárez, en la Sección I de la Investigación XXIX de las Disputaciones Metafísicas. La referencia a Suárez en este artículo no es gratuita. El propio Hobbes se refiere a él, de manera despectiva, por el tratamiento que hace de las relaciones causales: "¿Qué significado tiene las palabras La primera causa no influye necesariamente en la segunda, por fuerza de la esencial subordinación de las causas segundas, mediante la cual puede ayudarla a operar? Dichas palabras son la traducción del título del capítulo sexto del libro primero de la obra de Suárez Sobre el concurso, movimiento y ayuda de Dios. Cuando hay hombres que escriben volúmenes enteros con esa bazofia, ¿es que no están locos y tratan que otros también lo estén?” (Leviatán, parte I, cap. 8 [p.77]). No obstante, coincide con él en compartir dicha incomodidad, como también en apelar al mismo argumento.

8. Recuérdese que por conocer, Hobbes quiere decir conocer las relaciones causales.

9. La memoria trae inconvenientes consigo, a saber, es un sentido debilitado, ya que es un sentido que "se ha marchitado, que es viejo y pasado" (Leviatán, parte I, cap. 2).

10. Lo cual define como modos de concebir un cuerpo (De Corpore, cap. 8, art. 2).

11. La explicación del Aquinatense es compleja. En líneas generales, indica que el mundo (físico) indudablemente es creado, tal cual se aprecia en las Sagradas Escrituras. No obstante, es eterno, en cuanto que Dios tiene una idea de dicho mundo, por lo que la idea de mundo es eterna, dada la eternidad de Dios, ya que ninguna parte de Dios (incluyendo sus ideas) puede ser temporal, dado que afectaría la totalidad del ente divino. En este sentido, el mundo es tanto eterno (por ser una idea), como también no-eterno (por haber sido creado).

12. Ni siquiera el hombre: cuando alguien desea algo se debe al contacto con algo exterior que le ha causado un movimiento interno, que el Malmesburiense denominó pasión (Leviatán, parte I, cap. 6 [p.54]).

13. No hay que olvidar que tales ficciones (al igual que las imágenes) tienen su origen en las sensaciones, solo que se han corrompido o mezclado con otras que igualmente proceden de la experiencia. El ejemplo que Hobbes utiliza es el del centauro (Leviatán, parte I, cap. 2).

14. Recuérdese que, en vida, Hobbes tuvo problemas por las acusaciones de ateísmo que se hacían en su contra. Cuatro años después de su muerte, en 1683, la Universidad de Oxford proscribió y mandó a la hoguera varias de sus obras, entre ellas el Leviatán y De Cive (Mellizo, en Hobbes, 2001, p. viiii). Además, la propia Iglesia Católica, mediante "la Santa Congregación las añadió al Index" (Solano-Fallas, 2015, p. 104).

\section{Bibliografía}

Abbagnano, Nicola. (1966). Diccionario de Filosofía. México: Fondo de Cultura Económica.

Alfonso, Jorge. (2011). "La idea de Religión en Hobbes. Su importancia política". Pensamiento, 67(253), 389-405.

Arvon, Henri. (1969). El Ateísmo. Barcelona: Fontanella.

Bobbio, Norberto y Bovero, Michelangelo. (1986). Sociedad y Estado en la filosofía política moderna. El modelo iusnaturalista y el modelo hegeliano-marxiano. México, D. F.: Fondo de Cultura Económica.

Bolaños-González, Mireya. (2010). "Iusnaturalismo en Hobbes y en Locke”. Repositorio Institucional de la Universidad de Los Andes (Venezuela), 1-26.

Copleston, Frederick. (1983). Historia de la Filosofía. Vol. V. De Hobbes a Hume. Barcelona: Ariel.

Defez i Marti, Antoni. (2002). "Hobbes y el problema del realismo metafísico". Logos. Anales del Seminario de Metafísica, 35, 273-296. 
Fallas, Luis. (1994). "El poder de las palabras. Una interpretación de las relaciones entre el nominalismo y el pensamiento político de Hobbes". Revista de Filosofía de la Universidad de Costa Rica, 32(78-79), 144-154.

Fernández-García, Eusebio. (1983). "El contractualismo clásico (siglos XVII y XVIII) y los derechos naturales". Anuario de Derechos Humanos, (2), 59-100.

Ferrater Mora, José. (1944). Diccionario de Filosofía. México: Atlante.

Ferrater Mora, José. (1998). Diccionario de Filosofía. Tomo III. (K-P). Barcelona: Ariel.

Glover, Willis. (1965). "God and Thomas Hobbes". En K. C. Brown (Ed.), Hobbes Studies. Massachusets: Harvard University Press.

Hirschberger, Johannes. (1966). Historia de la Filosofía. Tomo II. Edad Moderna, Edad Contemporánea. Barcelona: Herder.

Hobbes, Thomas. (1741). "An Answer to a Book Published by Dr. Bramhall, Late Bishop of Derry; Called the Catching of the Leviathan". En William Molesworth (Ed.), The English Work of Thomas Hobbes of Malmesbury. Volumen IV. Londres: John Bohn.

Hobbes, Thomas y Descartes, René. (1952). “The third set of objections with the author's replies”. En R. Descartes, Rules for the Direction of the Mind, Discourse on the Method, Meditations on First Philosophy, Objections against the Meditations and Replies, The Geometry; Spinoza, Benedict de: Ethics. Chicago-London-Toronto: Encyclopedia Britannica.

Hobbes, Thomas y Descartes, René. (1977). "Terceras objeciones hechas por un célebre filósofo inglés con las respuestas del autor". En R. Descartes, Meditaciones metafísicas con objeciones y respuestas. Madrid: Alfaguara.

Hobbes, Thomas. (2000). Tratado sobre el Cuerpo. Madrid: Trotta.

Hobbes, Thomas. (2001). Leviatán, o de la Materia, Forma y Poder de un Estado Eclesiástico y Civil. Madrid: Alianza.

Hobbes, Thomas. (s. f.). Capítulos XV-XVIII (concernientes a la religión) de "De Cive". Hobbes: Antología. Barcelona: Península.

Moya-Bedoya, Juan Diego. (2003). "La teología agnóstica y apofática de Thomas Hobbes de Malmesbury". Revista de Filosofía de la Universidad de Costa Rica, 41(103), 127-136.

Moya-Bedoya, Juan Diego. (2012). Clase magistral del curso "Filosofía y Ateísmo en el mundo moderno" (SP-0691) del Programa de Posgrado en Filosofía de la Universidad de Costa Rica. Impartido el primer semestre del año 2012.

Oakeshott, Michael. (2000). "La vida moral en la obra de Thomas Hobbes". En M. Oakeshott, El Racionalismo en Política y Otros Ensayos. México: Fondo de Cultura Económica.

Ribeiro, Renato Janine. (2007). “Thomas Hobbes o la paz contra el clero”. En Atilio Boron (compilador), La filosofía política moderna. De Hobbes a Marx. La Habana: Ciencias Sociales.

Sabine, George H. (1975). Historia de la Teoría Política. México: Fondo de Cultura Económica. 
Solano-Fallas, Andrés. (2015). "Tentativa de ateísmo: La peligrosidad del uso de las matemáticas en el siglo XVII". Revista Interdisciplinaria Veritatem, 1(1), 93-112.

Tönnies, Ferdinad. (1932). Vida y Doctrina de Tomás Hobbes. Madrid: Revista de Occidente.

Zarka, Yves Charles. (1997). Hobbes y el Pensamiento Político Moderno. Barcelona: Herder.

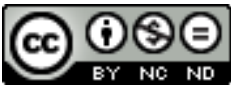

Esta obra está bajo una licencia de Creative Commons Reconocimiento-NoComercial-

SinObraDerivada 4.0 Internacional 